\title{
Effects of direct stray current on the performance of cathodic disbonding epoxy powder coatings
}

\author{
Yan-Yu Cui ${ }^{1} \cdot$ Rui-Tao Bu ${ }^{1} \cdot$ De-You Wang ${ }^{1} \cdot$ Yu-Jun Wang ${ }^{2}$
}

Received: 5 November 2018 / Published online: 11 October 2019

(c) The Author(s) 2019

\begin{abstract}
The influence of the direction and magnitude of direct (DC) stray current on the disbonding performance of epoxy powder coating was studied by using electrochemical impedance spectroscopy and scanning electron microscopy technology. The results show that the application of DC stray current could accelerate the anodic dissolution. The peeling degree of the coating increases as the magnitude of positive DC stray current interference increases in the range of 2-8 V. With $16 \mathrm{~V}$ positive stray current disturbance, the degree of coating disbonding decreases. With the application of negative stray current, the coating peeling becomes more serious, and the degree of peeling increases as the DC stray current increases.
\end{abstract}

Keywords Epoxy powder coating $\cdot$ DC stray current $\cdot$ Coating disbanding

\section{Introduction}

At present, buried pipelines are mostly protected against corrosion by using anti-corrosion coating combined with cathodic protection (Wang et al. 2018; Bin Muhd Noor et al. 2018). The most commonly used external anti-corrosive coating is fusion-bonded epoxy powder coating and three layers of polyethylene coating (Xi 2008). Epoxy powder coating is widely used for the protection of long-distance transmission pipelines due to its good corrosion resistance and environmental adaptability (Rahsepar et al. 2015; Gamboa et al. 2013). However, with the time extension of service, defects such as scratches and pinholes may occur, which will have a seriously influence on the protective effect of the coating. In the marine environment, water, oxygen and chloride permeation and temperature will have a great impact on the coating properties of oil and gas pipeline (Miszczyk and Schauer 2004; Park et al. 2003). Therefore, the method of increasing the output current and the electrification potential

\section{Edited by Xiu-Qiu Peng}

Yan-Yu Cui

yycui@cauc.edu.cn

1 College of Airport, Civil Aviation University of China, Tianjin 300300, People's Republic of China

2 Beijing Aviation Oil Construction Limited Company, Beijing 100012, China is used to strengthen corrosion protection in the process of pipeline operation (Oliveira and Ferreira 2003; Rahsepar et al. 2015; Teng et al. 2018). In addition, an excessively high potential could lead to over-protection of the pipeline and cause the formation of excess hydroxide ion $\left(\mathrm{OH}^{-}\right)$in the cathode region, which can decrease the binding force between the coating and the metal, and cause the peeling of the coating, namely cathodic disbanding ( $\mathrm{Li}$ and Bailey 2012). Considering the relation between cathode oxygen reduction and cathode stripping under surface coating of low-carbon steel, the interface alkalinization generated by oxygen reduction reaction may lead to the peeling of coating (Bi and Sykes 2015). According to the method of scanning vibrating electrode technology (SVET), with the application of cathodic protection, the calcareous film formed at the defect of the coating is beneficial to the cathodic protection process (Shi and Lyon 2017). The phenomenon of cathodic peeling of the coating could easily occur when the coating is partially damaged or leak (Sørensen et al. 2010; Lee et al. 2013; Yan et al. 2014). The peeling of the coating makes more corrosive medium penetrate deeper from the damaged position, causing the interface corrosion under the coating covering area. Cathodic protection results in a decrease in the impedance of intact epoxy varnish coating, and the water absorption of the coating rises owing to the increase in cathodic protection potential (Eltai et al. 2012). With the extension of soaking time, the peeling failure phenomenon of the coating will be more obvious, eventually leading to 
the complete failure of the coating and serious metal corrosion under the coating (Deflorian and Rossi 2006). However, systems using coatings and cathodic protection require careful control of the degree of cathodic protection to avoid the accelerating cathodic disbondment of the coating due to excessive cathodic protection current (Parhizkar et al. 2018a, b; Li et al. 2017). Aiming at the above problems, the relevant researches are carried out in the laboratory in accordance with the actual situation of the site. For example, the American Natural Gas Association commissions the Columbia Laboratory to study "Cathodic Protection under Peeling Anticorrosion," showing that the peeling of the coating layer shields the cathodic protection current and leads to the potential gradient under the coating. The simulation experiment is carried out on the process of "cathodic polarization under peeling and anticorrosion" by the corrosion control of the Arab American Petroleum Company of Saudi Arabia. Early studies suggest that cathodic disbonding is due to the cathodic reduction reaction of oxides with the defects of the pipe coating, resulting in the formation of excess $\mathrm{OH}^{-}$. The alkaline environment destroys the epoxy component of the coating and the metal surface, as well as decreasing the adhesion force (Kim and Chai 2018; Kendig et al. 1990; Fürbeth and Stratmann 2001). Cathodic polarization potential, pigmentation, filler and surface treatment conditions all have effects on the cathodic disbondment of the coating (Yao et al. 2014; Nikravesh et al. 2011; Naderi and Attar 2010; Rani et al. 2012; Mahdavian and Ashhari 2010). Some researchers believe that the increase in the $\mathrm{pH}$ in the cathode region can cause the cathode of the base metal oxide bonded to the anti-corrosion layer to be peeled off, and at the same time, the anti-corrosion layer of the pipeline is dissolved, or the adhesion between polymer and metal is lowered, thereby the corrosion layer produces cathodic disbondment. Luo et al. (1997) found that a delay existed in the cathodic stripping process of the anti-corrosion layer. Cathodic polarization in the early cathodic stripping stage is not a certain dominant factor, but the interface between anti-corrosion layer and metal is a more important reactive substance. Exchange routes and anti-corrosion defects are dominant factors in horizontal exchange.

During the pipeline operation, some of the direct current generated by the electrified traction system and the welding equipment near the pipeline will flow into the pipeline, and the protection current generated by the cathodic protection facility will also produce stray current. The stray current flows into the pipe and undergoes electrochemical corrosion at pipe exit. Studies have found that current density, chloride ion concentration, etc. could affect stray current corrosion (Li et al. 2017; Bertolini et al. 2007; Sørensen et al. 2010). In addition, the magnitude and direction of stray current will inevitably affect the corrosion. However, there are relatively few studies on the anti-cathode disbonding performance of epoxy powder coatings interfered by DC stray current.

Therefore, the experimental study on the anti-cathode disbonding performance of epoxy powder coating has been conducted in this paper. The law of electrochemical impedance spectroscopy with time after applying DC stray current of different magnitudes and directions was analyzed. The basic rule of the anti-cathode disbonding performance of the coating has been analyzed.

\section{Experimental}

\subsection{Experimental sample excitation and ionization}

The test samples had a dimension of $150 \mathrm{~mm} \times 150 \mathrm{~mm} \times 10 \mathrm{~mm}$, which were cut from a Q235 steel pipe with an epoxy powder coating of $400 \mu \mathrm{m}$ thick. Coating defects on the samples were detected with an electric spark leak detector whose voltage was set at $2000 \mathrm{~V}$. Before starting the cathodic disbonding experiments, we need to test the coating quality of the test samples measured by an electric spark leak detector (JC-6) from Wenzhou Jingcheng Metering Equipment Co., Ltd. The samples qualified for the spark test can be used for the cathodic disbonding tests. Three parallel samples were used for each set of cathodic disbonding experiments to ensure experimental repeatability.

\subsection{Experimental methods}

As shown in Fig. 1, a blind hole with a diameter of $3.2 \mathrm{~mm}$ was drilled at the center of the test sample to expose the metal substrate as the working electrode for electrochemical tests. A PVC pipe with a diameter of $75 \mathrm{~mm}$ and a length of $12 \mathrm{~cm}$ was used to hold an electrolyte solution in the electrochemical test experiment system and the cathodic protection system as shown in Fig. 1. The center of the PVC pipe was aligned with the center of the blind hole at the center of the sample. The bottom of the PVC pipe was bonded to the sample, and the simulated etching liquid was injected through the upper opening. One corner of the sample is polished to remove the anti-corrosion layer to connect the working electrode of the electrochemical workstation (CHI660D) from Beijing Huake Putian Technology Co., Ltd., or to connect the negative pole of the DC power supply (MCH-305DII) from Shandong Jingjiu Technology Co., Ltd. In the electrochemical test experiment as shown in Fig. 1a, three-electrode systems were adopted. The working electrode was a metal-coating system, a platinum electrode was used as the auxiliary electrode, and a saturated calomel electrode was used as the reference electrode. In the cathodic protection system 


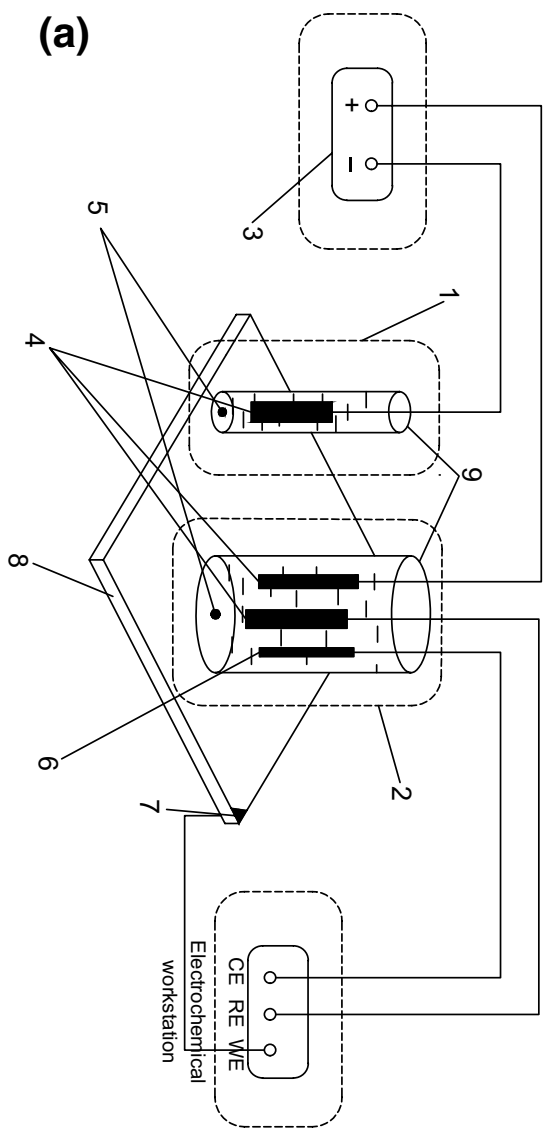

Fig. 1 Experimental device diagram

as shown in Fig. 1b, the cathodic protection potential was controlled at $-3.5 \mathrm{~V}$. As shown in Fig. 1b, the negative pole of the DC power supply was connected to the corner of the test sample and the positive pole was connected to the platinum electrode. A $10 \mathrm{~mm} \times 10 \mathrm{~mm}$ area was selected in another corner corresponding to the corner removed the coating of the test sample, and a blind hole with a diameter of $3.2 \mathrm{~mm}$ was drilled at the center of the region, exposing the metal substrate as a current path for applying DC stray current in the auxiliary system as shown in Fig. 1. A PVC pipe with a diameter of $25 \mathrm{~mm}$ and a length of $12 \mathrm{~cm}$ was used to hold the electrolyte solution in the auxiliary system. The center of the PVC pipe was aligned with the center of the blind hole at the edge of the sample. A DC stabilized power supply was used to provide stray current. The positive stray current flowed from the auxiliary system to the electrochemical test experiment system, but the negative stray current flowed inversely from the electrochemical test experiment system to the auxiliary system.

A $3 \% \mathrm{NaCl}$ solution preheated to $65^{\circ} \mathrm{C}$ was poured into two PVC tubes, and the height of the $\mathrm{NaCl}$ solution was set at three-fourths of the tube height. The experimental

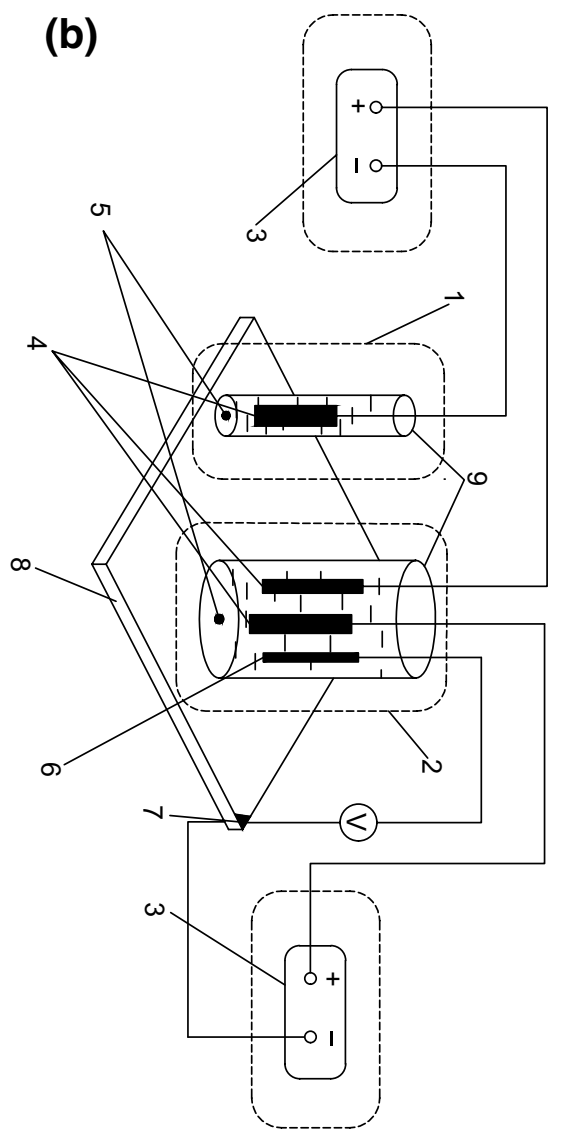

temperature was controlled at $65{ }^{\circ} \mathrm{C}$ during the experimental period of $48 \mathrm{~h}$.

\subsection{Experimental program}

In this paper, the effect of the direction and magnitude of DC stray current on the cathodic disbondment of the coating was investigated. Therefore, the experiment was divided into two groups.

Group A As shown in Fig. 1a, the wires 1 and 2 were, respectively, connected to the negative and positive terminals in the auxiliary system. The current flowed from the auxiliary system to the experimental system, which was called current positive inflow. The DC stray current interference voltage was applied with $2 \mathrm{~V}, 4 \mathrm{~V}, 8 \mathrm{~V}$ or $16 \mathrm{~V}$, respectively.

Group B As shown in Fig. 1, the wires 1 and 2 were, respectively, connected to the positive and negative terminals in the auxiliary system. The current flowed from the experimental system to the auxiliary system, which was called current negative inflow. The DC stray current interference voltage was applied with $2 \mathrm{~V}, 4 \mathrm{~V}, 8 \mathrm{~V}$ or $16 \mathrm{~V}$, respectively. 


\subsection{Electrochemical test}

As shown in Fig. 1a, electrochemical tests were completed with the electrochemical workstation. The test frequency of the electrochemical impedance spectroscopy (EIS) was from $0.1 \mathrm{~Hz}$ to $100 \mathrm{kHz}$, and the amplitude was $10 \mathrm{mV}$. DC interference was interrupted during electrochemical measurement. Electrochemical test results were fitted with ZsimpWin software. After the experiment, the cathode disbonding distance was calculated to $0.1 \mathrm{~mm}$ accurately in accordance with the requirement in SY/T 0315-2013.

\subsection{Corrosion morphology analysis}

After the experiment, the test samples were naturally dried on the test bench. The corrosion morphology of the test samples after being cooled to room temperature was observed with the scanning electron microscope (SEM) (Quanta FEG250) from Czech FEI, and the elemental composition of the surface corrosion products was analyzed by an energydispersive spectrometer.

\section{Results and discussion}

\subsection{Effect of positive DC stray current}

The evolution of EIS with time under $2 \mathrm{~V}$ DC interference is shown in Fig. 2. The EIS obtained at high frequencies reflects the information of the coating and corrosion products, and the EIS at low frequencies reflects the information of the electrode itself participating in the reaction. As shown in Fig. 2, the high-frequency bands show that the end of the impedance arc shifts to the right direction with time due to

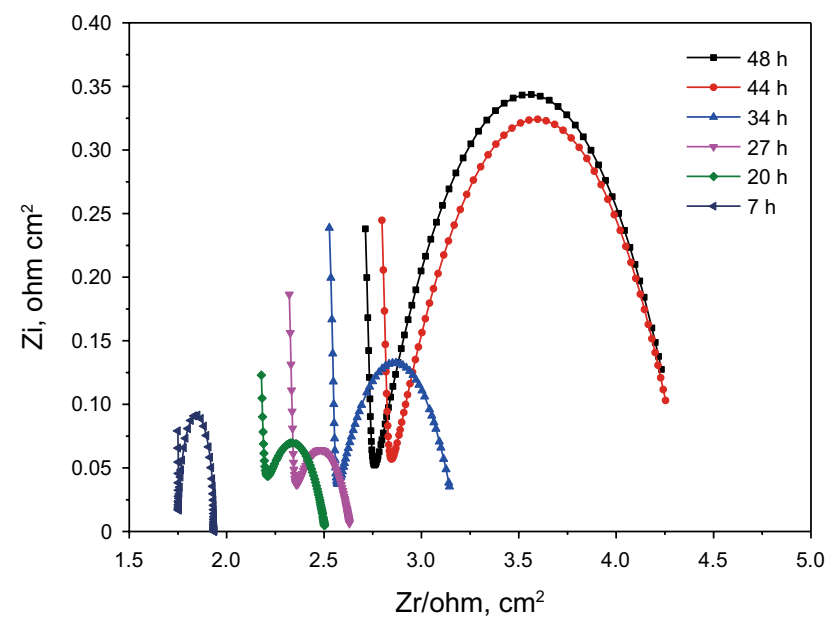

Fig. 2 Nyquist diagrams of cathodic disbanding samples under DC interference voltage of $2 \mathrm{~V}$ the synergies, the performance change in the coating and the corrosion products formed on the metal surface in the defect hole. At the low-middle-frequency region, there existed an irregular semicircle arc, and the arc radius tended to increase with the immersion time.

Under the DC interference voltage of $2 \mathrm{~V}$, the circuit $(\mathrm{C}(\mathrm{R}(\mathrm{RC})))$ is used as fitting model at $7 \mathrm{~h}$ as shown in Fig. 3, and the circuit $(\mathrm{C}(\mathrm{R}(\mathrm{RW})))$ is used as fitting model within 20-48 $\mathrm{h}$ as shown in Fig. 4. The fitting results are given in Table 1. At the beginning of the test, the medium solution reaches the intersection of the coating and the metal interface. The $C_{\mathrm{dl}}$ represents electric double-layer capacitor, and $R_{\mathrm{t}}$ represents charge transfer resistor. The $C_{\mathrm{c}}$ represents coating capacitor and $R_{\mathrm{c}}$ represents coating resistance. The W represents diffusion impedance of Warburg. The $C_{\mathrm{dl}}$ and $R_{\mathrm{t}}$ mainly reflect the transformation of the charge between the metal and solution interface. At the same time, the medium solution is also infiltrated into the metal surface through the coating, and $C_{\mathrm{c}}$ and $R_{\mathrm{c}}$ mainly reflect the permeability of the corrosive medium and the degree of disbonding of the coating between metal substrate and coating in the process. As the solution of the medium continues to pass through the gap between the coating and metal substrate, the medium

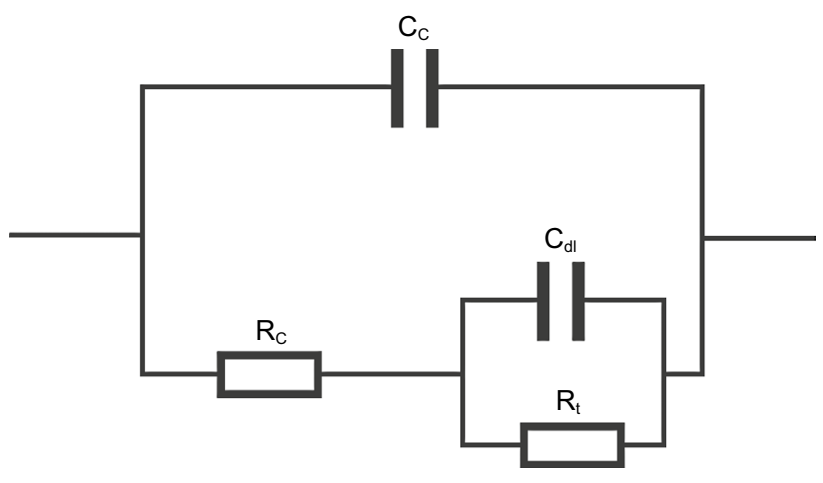

Fig. 3 Equivalent circuit model $(\mathrm{C}(\mathrm{R}(\mathrm{RC})))$

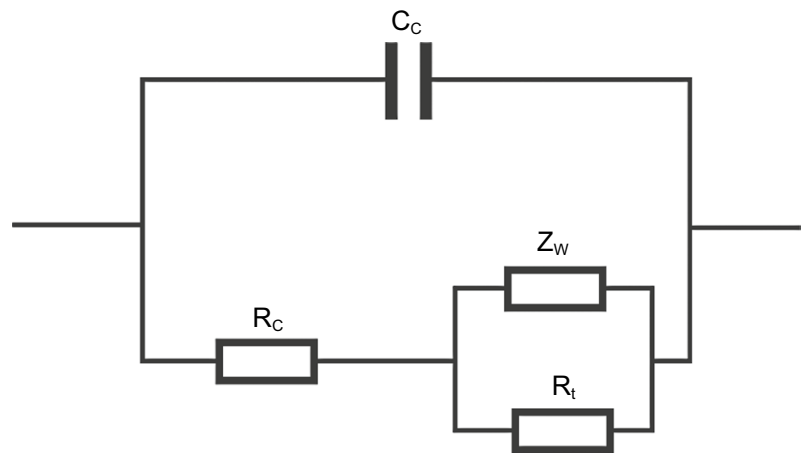

Fig. 4 Equivalent circuit model $(\mathrm{C}(\mathrm{R}(\mathrm{RW})))$ 
Table 1 Circuit element fitting value with DC interference voltage of $2 \mathrm{~V}$

\begin{tabular}{llllll}
\hline $\begin{array}{l}\text { Experimental } \\
\text { time, h }\end{array}$ & $\begin{array}{l}\text { Coating capacitor } \\
C_{\mathrm{c}}, \mathrm{F} \mathrm{cm} \mathrm{cm}^{-2}\end{array}$ & $\begin{array}{l}\text { Coating resistance } \\
R_{\mathrm{c}}, \Omega \mathrm{cm}^{2}\end{array}$ & $\begin{array}{l}\text { Electric double-layer } \\
\text { capacitor } R_{\mathrm{t}}, \Omega \mathrm{cm}^{2}\end{array}$ & $\begin{array}{l}\text { Electric double-layer } \\
\text { capacitor } C_{\mathrm{d}}, \mathrm{F} \mathrm{cm} \mathrm{cm}^{-2}\end{array}$ & $\begin{array}{l}\text { Diffusion impedance } \\
\text { of Warburg } W, \Omega \mathrm{cm}^{2}\end{array}$ \\
\hline 7 & $4.914 \mathrm{E}-8$ & 1.753 & 18.24 & 0.00214 & - \\
20 & $4.496 \mathrm{E}-8$ & 2.172 & 0.3347 & - & 0.07589 \\
27 & $6.371 \mathrm{E}-6$ & 2.329 & 0.3086 & - & 0.1263 \\
34 & $6.962 \mathrm{E}-8$ & 2.544 & 0.6401 & - & 0.1579 \\
44 & $5.72 \mathrm{E}-8$ & 2.807 & 1.565 & - & 0.08741 \\
48 & $5.938 \mathrm{E}-8$ & 2.724 & 1.659 & - & 0.09919 \\
\hline
\end{tabular}

solution passes through the gap between the particles. The characteristics of the Warburg impedance on the impedance spectrum exhibit due to the blocking of particles such as fillers in the coating. The $\mathrm{W}$ characterizes a situation in which mass transfer (dielectric solution diffusion) processes are hindered. Since the diffusion of the medium solution is formed between the coating and the metal substrate, it can be known that the coating has been peeled off at this time.

It is known from Table 1 that the value of $R_{\mathrm{t}}$ decreases sharply from 7 to $20 \mathrm{~h}$, and this is because that the gap between the metal and the coating is very small at $7 \mathrm{~h}$, which represents that the disbonding degree is very small and the transfer resistance of the reaction charge is larger. When the test lasts for $20 \mathrm{~h}$, the charge transfer channel increases because of the increase in the gap between the coating and the metal, so the impedance is greatly reduced. As the reaction continues, there is a small increase in impedance from 20 to $48 \mathrm{~h}$, and this is due to the inhomogeneity of the coating performance resulting in the unbalance of the disbonding zone of the coating, which leads to the increase in resistance in the process of charge transfer. When the test samples are soaked for $20 \mathrm{~h}$, the equivalent circuit appears Warburg impedance, and this is because the medium solution enters the metal surface through the gap between the coating and metal and it is blocked by fillers and other particles in the coating. The interface corrosion reaction is mainly determined by the mass transfer diffusion process. From Table 1, the value of $\mathrm{W}$ becomes larger and then fluctuates, and this is because that in the range of 20-34 h, the mass transferring in this process is hindered by a variety of fillers, pigments and some flaky obstacle in the organic coating. Since the coating disbonding progresses radially to the periphery, the obstructions encountered during the mass transfer process gradually increase, and the $\mathrm{W}$ impedance increases. After $34 \mathrm{~h}$, the value of $\mathrm{W}$ becomes smaller and has a tendency to fluctuate, and this is due to the fact that although the disbonding area increases, the adhesion effect of the coating on the metal surface is nonuniform, which leads to the rapid propagation of the medium in a certain direction or several directions, and the ultimate performance is the decrease in impedance.
The evolution of impedance spectrum with time under DC interference voltage of $4 \mathrm{~V}$ is shown in Fig. 5. The variation of impedance spectrum at high frequencies with $4 \mathrm{~V}$ DC interference is similar to that with $2 \mathrm{~V} \mathrm{DC}$ interference, and the fluctuation of its high-frequency arc is larger, which indicates that more severe metal corrosion occurred under $4 \mathrm{~V}$ DC interference. In the middle- and low-frequency region, the radius of the arc in Fig. 5 first decreased and then increased. When the immersion time reached $44 \mathrm{~h}$ or $48 \mathrm{~h}$, a slight decrease occurred.

Under the condition of $4 \mathrm{~V}$ DC interference, the circuit $(\mathrm{C}(\mathrm{R}(\mathrm{RC})))$ is fitted for Nyquist diagrams at $7 \mathrm{~h}$, and the circuit $(\mathrm{C}(\mathrm{R}(\mathrm{RW})))$ is fitted for Nyquist diagrams from 20 to $48 \mathrm{~h}$. The fitting results are given in Table 2. According to the fitting results, the value of $R_{\mathrm{t}}$ is relatively small before $34 \mathrm{~h}$ and increases by about 50 times at $44 \mathrm{~h}$. This indicates that the coating has been stripped to a certain extent at the initial stage, and the reaction charge has transferred between the coating and the metal substrate, but the resistance is relatively small. When the reaction proceeds for $44 \mathrm{~h}$, the corrosion products are continuously deposited as the coating is further stripped. The charge

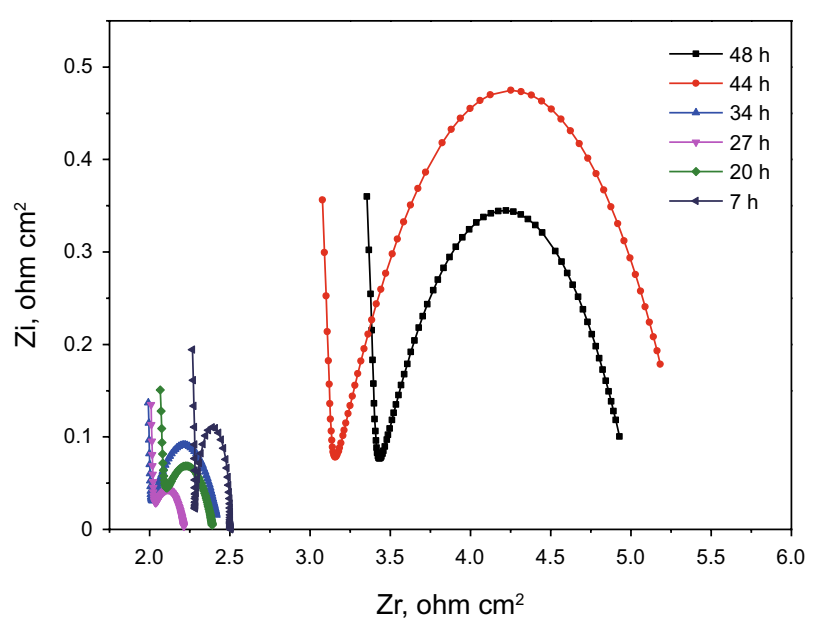

Fig. 5 Nyquist diagrams of experimental system under DC interference voltage of $4 \mathrm{~V}$ 
Table 2 Circuit element fitting value with DC interference voltage of $4 \mathrm{~V}$

\begin{tabular}{llllll}
\hline $\begin{array}{l}\text { Experimental } \\
\text { time, h }\end{array}$ & $\begin{array}{l}\text { Coating capacitor } \\
C_{\mathrm{c}}, \mathrm{F} \mathrm{cm}\end{array}$ & $\begin{array}{l}\text { Coating resistance } \\
R_{\mathrm{c}}, \Omega \mathrm{cm}^{2}\end{array}$ & $\begin{array}{l}\text { Electric double-layer } \\
\text { capacitor } R_{\mathrm{t}}, \Omega \mathrm{cm}^{2}\end{array}$ & $\begin{array}{l}\text { Electric double-layer } \\
\text { capacitor } C_{\mathrm{d}}, \mathrm{F} \mathrm{cm} \mathrm{cm}^{-2}\end{array}$ & $\begin{array}{l}\text { Diffusion impedance } \\
\text { of Warburg } W, \Omega \mathrm{cm}^{2}\end{array}$ \\
\hline 7 & $7.215 \mathrm{E}-8$ & 2.285 & 0.2198 & 0.0029 & - \\
20 & $6.271 \mathrm{E}-8$ & 2.066 & 0.3298 & - & 0.0804 \\
27 & $6.126 \mathrm{E}-8$ & 2.011 & 0.2064 & - & 0.1469 \\
34 & $6.324 \mathrm{E}-8$ & 1.994 & 0.4409 & - & 0.1535 \\
44 & $6.877 \mathrm{E}-8$ & 3.103 & 2.292 & - & 0.0664 \\
48 & $5.859 \mathrm{E}-8$ & 3.379 & 16.65 & - & 0.0675 \\
\hline
\end{tabular}

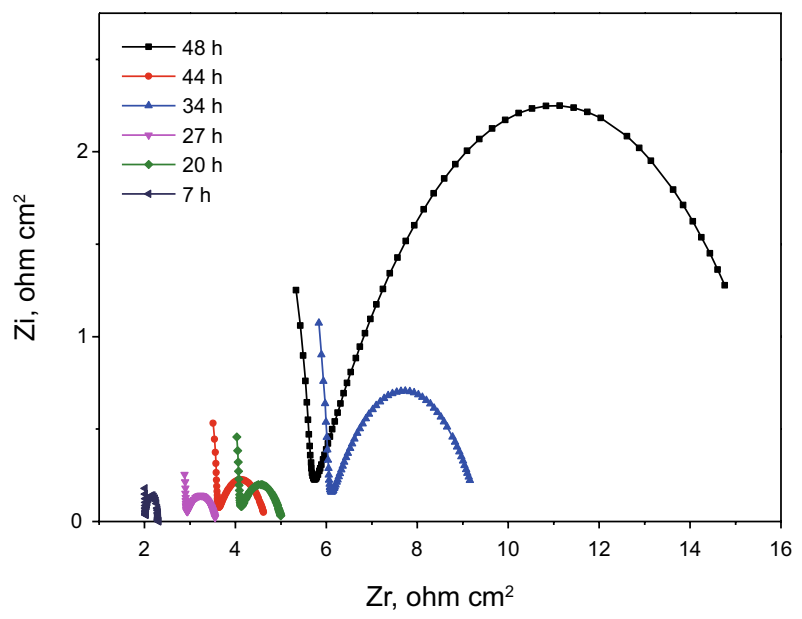

Fig. 6 Nyquist diagrams of experimental system with DC interference voltage of $8 \mathrm{~V}$

transfer encounters a large number of obstacles, which leads to the increase in the transfer resistance. With the progress of reaction, the superposition effect of obstacles increases at $48 \mathrm{~h}$. The value of $\mathrm{W}$ increases first and then decreases. This is because that during the soaking process from 20 to $34 \mathrm{~h}$, the degree of coating disbonding gradually increases, and the obstacles encountered in the mass transfer process increase. After $34 \mathrm{~h}$, the degree of coating disbonding increases sharply, resulting in the decrease in medium diffusion impedance.
The evolution of EIS with time under DC interference voltage of $8 \mathrm{~V}$ is shown in Fig. 6. The fluctuation of the impedance value over time significantly increases compared with that under $2 \mathrm{~V}$ or $4 \mathrm{~V} \mathrm{DC}$ interference. The radius of the low-frequency zone fluctuates with time, and the amplitude is also increasing. The curves are fitted with the circuit diagrams in Figs. 3 and 4, and the results are given in Table 3. The value of $R_{\mathrm{c}}$ is determined by both the coating resistance and the deposited corrosion products. Under $8 \mathrm{~V}$ DC interference, the value of $R_{\mathrm{c}}$ is greater than that of $2 \mathrm{~V}$ or $4 \mathrm{~V}$ interference. In the process of reaction, the resistance of coating gradually decreases with the deterioration of the coating performance. The increase in the value of $R_{\mathrm{c}}$ indicates that the deposition phenomenon of the corrosion products is more pronounced, i.e., the dissolution reaction of the anode is more severe. In addition, the value of $R_{\mathrm{t}}$ increases rapidly in a short period of time, indicating that the disbonding speed of the coating increases and the degree of disbonding increases during the test time. The $\mathrm{W}$ value is an order of magnitude smaller than that of $2 \mathrm{~V}$ or $4 \mathrm{~V}$ interference, and under the $8 \mathrm{~V} \mathrm{DC}$ interference, the degree of disbonding of the coating is increasing.

The evolution of EIS with time under $16 \mathrm{~V}$ DC interference is shown in Fig. 7. The impedance radius has a decreasing trend compared with previous experiments. The radius of the low-frequency arc is the largest at $7 \mathrm{~h}$, and then, it decreases first and then increases. The equivalent circuit $\mathrm{R}(\mathrm{CR})$ is fitted for the Nyquist diagrams at $7 \mathrm{~h}$ as shown in Fig. 8 and that is fitted with $\mathrm{R}(\mathrm{C}(\mathrm{R}(\mathrm{RC})))$ at $20 \mathrm{~h}$ as shown

Table 3 Circuit element fitting value with DC interference voltage of $8 \mathrm{~V}$

\begin{tabular}{llllll}
\hline $\begin{array}{l}\text { Experimental } \\
\text { time, h }\end{array}$ & $\begin{array}{l}\text { Coating capacitor } \\
C_{\mathrm{c}}, \mathrm{F} \mathrm{cm}\end{array}$ & $\begin{array}{l}\text { Coating resistance } \\
R_{\mathrm{c}}, \Omega \mathrm{cm}^{2}\end{array}$ & $\begin{array}{l}\text { Electric double-layer } \\
\text { capacitor } R_{\mathrm{t}}, \Omega \mathrm{cm}^{2}\end{array}$ & $\begin{array}{l}\text { Electric double-layer } \\
\text { capacitor } C_{\mathrm{d}}, \mathrm{F} \mathrm{cm} \mathrm{cm}^{-2}\end{array}$ & $\begin{array}{l}\text { Diffusion impedance } \\
\text { of Warburg } W, \Omega \mathrm{cm}^{2}\end{array}$ \\
\hline 7 & $8.353 \mathrm{E}-8$ & 2.027 & 0.2802 & 0.00106 & - \\
20 & $5.195 \mathrm{E}-8$ & 4.065 & 0.9648 & - & 0.0638 \\
27 & $5.631 \mathrm{E}-8$ & 2.895 & 6.822 & - & 0.08842 \\
34 & $5.757 \mathrm{E}-8$ & 6.006 & 3.407 & - & 0.040 \\
44 & $7.961 \mathrm{E}-8$ & 3.58 & 1.091 & - & 0.08168 \\
48 & $7.814 \mathrm{E}-8$ & 5.592 & 10.86 & - & 0.02658 \\
\hline
\end{tabular}




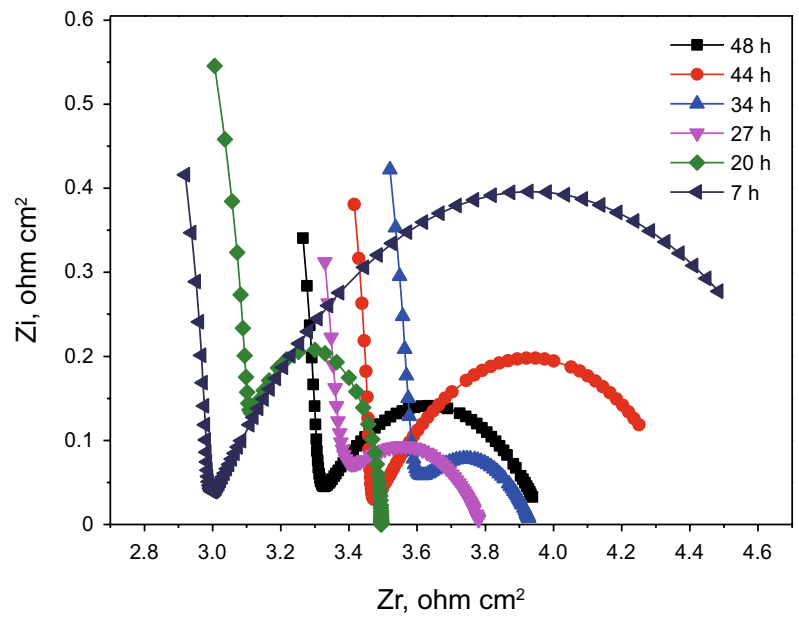

Fig. 7 Nyquist diagrams of experimental system under DC interference of $16 \mathrm{~V}$

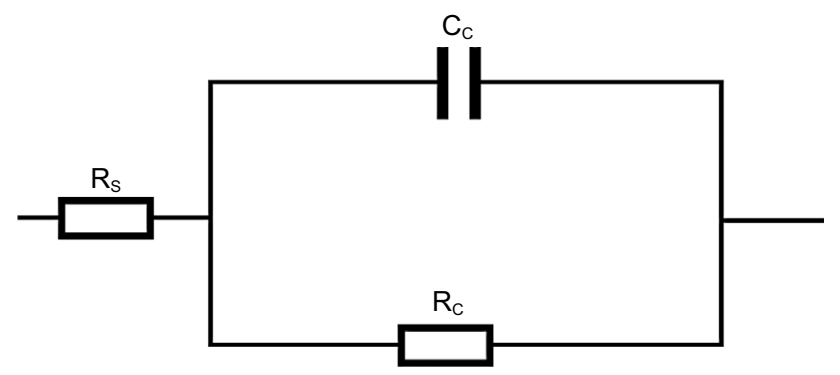

Fig. 8 Equivalent circuit model R(CR)

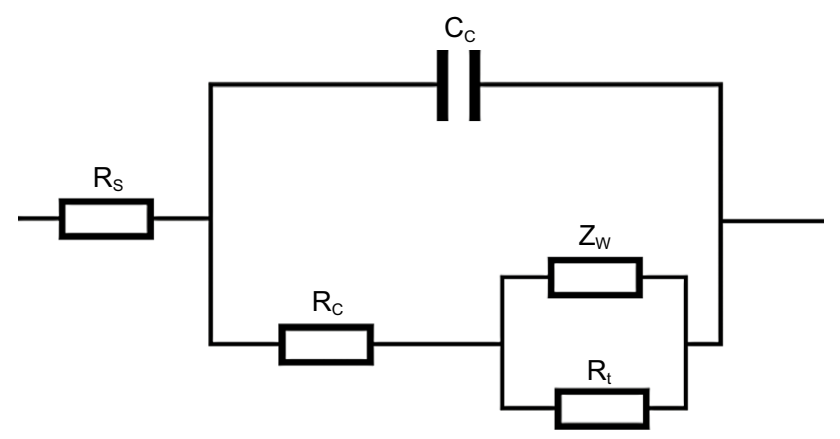

Fig. 9 Equivalent circuit model $\mathrm{R}(\mathrm{C}(\mathrm{R}(\mathrm{RC})))$

in Fig. 9. The other curves are fitted with the circuit diagram shown in Fig. 4. The fitting results are given in Table 4.

As given in Table 4, it can be seen that the value of $R_{\mathrm{c}}$ determined by the coating and the corrosion products fluctuates more significantly than that in the previous experiment. It can be judged that the corrosion of metal is the most serious under the $16 \mathrm{~V}$ DC interference. The charge transfer resistance $\left(R_{\mathrm{t}}\right)$ decreases significantly in the range of 20-27 h, indicating that the charge transfers between the coating and the metal are easy at this stage and showing that the coating is stripped during this period of time. According to the selection of the fitting circuit, the $\mathrm{W}$ only appears at $27 \mathrm{~h}$, indicating that the disbonding time of the coating is relatively late or the disbonding degree is weak under the $16 \mathrm{~V}$ $\mathrm{DC}$ interference. The $\mathrm{W}$ value is small after $27 \mathrm{~h}$ and slightly increases at $48 \mathrm{~h}$, indicating that the coating is stripped, but the extent of disbonding increases nonsignificantly.

After finishing the electrochemical tests, the defect hole of the specimen is processed, and the disbonding distance of each test group is obtained as given in Table 5. At the end of the experiment, the cathode disbonding of the sample is shown in Fig. 10.

As given in Table 5 and shown in Fig. 10, the disbonding distance of specimens increases from 2 to $8 \mathrm{~V} \mathrm{DC}$ interference, and the disbonding distance decreases under $16 \mathrm{~V} \mathrm{DC}$ interference. This is consistent with the results shown in EIS.

\subsection{Effect of negative stray current}

The evolution of the impedance of the system with $-2 \mathrm{~V}$ DC interference is shown in Fig. 11. The arcs of the highfrequency section move left and right on the coordinate axis, indicating that the impedance of the high-frequency band changes greatly with time. It can be seen from the figure that whether positive DC stray current or negative DC stray current is applied, the right end of the high-frequency arc could not completely form a semicircular arc, and the lowfrequency arc starts to be derived, and this is because of the large defects in the experimental system. The corrosive medium will diffuse laterally along the interface between coating and metal substrate, which also penetrates the coating longitudinally to the interface. Both types of infiltration will work together to cause this phenomenon. The circuits within first $34 \mathrm{~h}$ are fitted with the circuit diagram shown in Fig. 3, and the circuit shown in Fig. 4 is selected at $44 \mathrm{~h}$ or $48 \mathrm{~h}$. The fitting results are given in Table 6.

As given in Table 6, the value of $R_{\mathrm{c}}$ fluctuates, and it represents the fluctuation of the impedance value of the coating and corrosion products, which is consistent with the law shown in Fig. 11. The resistance decreases from 7 to $20 \mathrm{~h}$, which is due to the gradual failure of the coating. From 20 to $48 \mathrm{~h}, R_{\mathrm{c}}$ fluctuates up and down, and this is the display of the coating disbonding. With the process of disbonding, the gap between the coating and the metal is increasing gradually, and there will be some areas in the gap that the medium cannot reach. Crevice corrosion is very likely to occur in these places and produce corrosion products. The fluctuation of $R_{\mathrm{c}}$ value is the result of the reaction of the cathode reaction and crevice corrosion. Before $44 \mathrm{~h}$, the $R_{\mathrm{t}}$ value has been between $0.1 \Omega \mathrm{cm}^{2}$ and $0.16 \Omega \mathrm{cm}^{2}$, indicating that between 7 and $44 \mathrm{~h}$, the difficulty of charge transfer is unchanged 
Table 4 Circuit element fitting value with DC interference of $16 \mathrm{~V}$

\begin{tabular}{lllllll}
\hline $\begin{array}{l}\text { Experimen- } \\
\text { tal time, h }\end{array}$ & $\begin{array}{l}\text { Solution resist- } \\
\text { ance } R_{\mathrm{s}}, \Omega \mathrm{cm}^{-2}\end{array}$ & $\begin{array}{l}\text { Coating capaci- } \\
\text { tor } C_{\mathrm{c}}, \mathrm{F} \mathrm{cm}^{-2}\end{array}$ & $\begin{array}{l}\text { Coating resist- } \\
\text { ance } R_{\mathrm{c}}, \Omega \mathrm{cm}^{2}\end{array}$ & $\begin{array}{l}\text { Electric double-layer } \\
\text { capacitor } R_{\mathrm{t}}, \Omega \mathrm{cm}^{2}\end{array}$ & $\begin{array}{l}\text { Electric double-layer } \\
\text { capacitor } C_{\mathrm{dl}}, \mathrm{F} \mathrm{cm} \mathrm{cm}^{-2}\end{array}$ & $\begin{array}{l}\text { Diffusion impedance } \\
\text { of Warburg } W, \Omega \mathrm{cm}^{2}\end{array}$ \\
\hline 7 & 0.2078 & $7.555 \mathrm{E}-7$ & 2.946 & - & - & - \\
20 & 0.4047 & $1.102 \mathrm{E}-6$ & 28.3 & 10.536 & - & - \\
27 & - & $3.542 \mathrm{E}-6$ & 11.34 & 4.287 & - & 0.02248 \\
34 & - & $2.947 \mathrm{E}-8$ & 10.82 & 5.879 & - & 0.01327 \\
44 & - & $2.794 \mathrm{E}-8$ & 14.52 & 4.263 & - & 0.05554 \\
48 & - & $5.974 \mathrm{E}-8$ & 3.294 & 6.806 & 0.1403 \\
\hline
\end{tabular}

Table 5 Disbonding distance of epoxy powder coating with positive DC interference

\begin{tabular}{llllll}
\hline DC interference, $\mathrm{V}$ & 0 & 2 & 4 & 8 & 16 \\
\hline Disbonding distance, mm & 4.5 & 5.9 & 6.2 & 6.5 & 4.7 \\
\hline
\end{tabular}

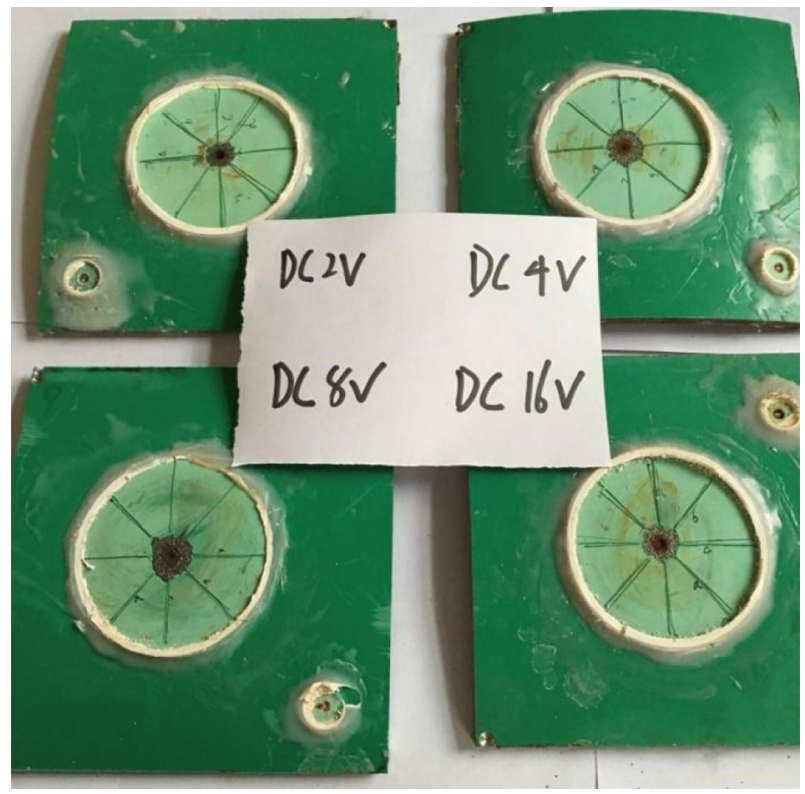

Fig. 10 Cathodic disbonding diagram with positive DC interference

significantly, and the transfer process is easy. At this time, the coating has been stripped, but it has not developed much. After $44 \mathrm{~h}$, the fitting circuit appears $\mathrm{W}$, which means that in this experimental system, the medium is transferred to a new stage. The medium solution is tangent to diffusion, and the $\mathrm{W}$ at $48 \mathrm{~h}$ is higher than that at $44 \mathrm{~h}$, and the corresponding charge transfer impedance $R_{\mathrm{t}}$ also increases by about 0.1 . All these show that the transfer resistance between the coating and the metal substrate is larger. The corrosion medium permeates, and the distance from the external corrosion medium to the metal substrate increases, which also shows that the disbonding degree of the coating becomes larger.

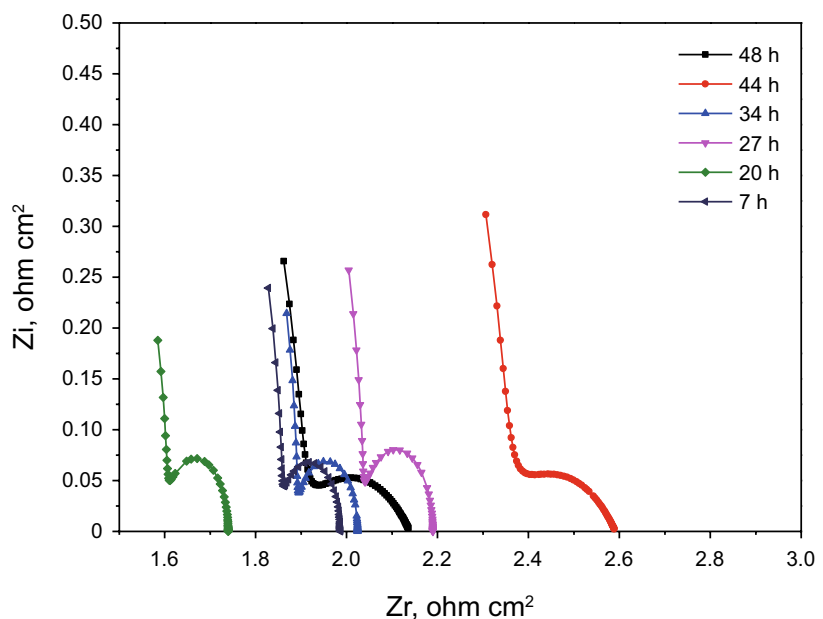

Fig. 11 Nyquist diagrams of experimental system under DC interference voltage of $-2 \mathrm{~V}$

The impedance evolution under $-4 \mathrm{~V}$ DC interference is shown in Fig. 12. Compared with that of $-2 \mathrm{~V}$ DC interference, the impedance range and impedance fluctuation increase significantly when $-4 \mathrm{~V}$ DC interference is applied. This is maybe that the DC interference voltage of $-4 \mathrm{~V}$ has a more significant effect on the disbonding of the coating at the defect hole of the coating, and it results in a greater degree of cathodic reaction and anode corrosion. The fitting results are given in Table 7.

As given in Table 7, the value of $R_{\mathrm{c}}$ at $27 \mathrm{~h}$ increases significantly. This is because the corrosion of metal substrate is aggravated, and it results in a large amount of products depositing on the metal surface, and it results in the increase in $R_{\mathrm{c}}$. During the period, the value of the charge transfer impedance $R_{\mathrm{t}}$ is small, because the coating has peeled off and the disbonding speed is larger. The value of $R_{\mathrm{c}}$ decreases significantly at $34 \mathrm{~h}$ and then gradually increases. This is because that the disbonding of the coating has entered a new stage, and the coating has a large extent of exfoliation. The large area failure of coating leads to a great reduction in the impedance of the coating. The increase in $R_{\mathrm{c}}$ after $34 \mathrm{~h}$ is due to the serious exfoliation of the coating and the increase 
Table 6 Circuit element fitting value under DC interference voltage of $-2 \mathrm{~V}$

\begin{tabular}{llllll}
\hline $\begin{array}{l}\text { Experimental } \\
\text { time, h }\end{array}$ & $\begin{array}{l}\text { Coating capacitor } \\
C_{\mathrm{c}}, \mathrm{F} \mathrm{cm}\end{array}$ & $\begin{array}{l}\text { Coating resistance } \\
R_{\mathrm{c}}, \Omega \mathrm{cm}^{2}\end{array}$ & $\begin{array}{l}\text { Electric double-layer } \\
\text { capacitor } R_{\mathrm{t}}, \Omega \mathrm{cm}^{2}\end{array}$ & $\begin{array}{l}\text { Electric double-layer } \\
\text { capacitor } C_{\mathrm{dl}}, \mathrm{F} \mathrm{cm} \mathrm{cm}^{-2}\end{array}$ & $\begin{array}{l}\text { Diffusion impedance } \\
\text { of Warburg } W, \Omega \mathrm{cm}^{2}\end{array}$ \\
\hline 7 & $1.346 \mathrm{E}-7$ & 1.859 & 0.1269 & 0.0009192 & - \\
20 & $1.399 \mathrm{E}-7$ & 1.607 & 0.1324 & 0.0005602 & - \\
27 & $1.203 \mathrm{E}-7$ & 2.038 & 0.1522 & 0.0008195 & - \\
34 & $1.161 \mathrm{E}-7$ & 1.893 & 0.1317 & 0.001135 & - \\
44 & $1.062 \mathrm{E}-7$ & 2.333 & 0.2581 & - & 0.06381 \\
48 & $1.399 \mathrm{E}-7$ & 1.89 & 0.2492 & - & 0.09557 \\
\hline
\end{tabular}

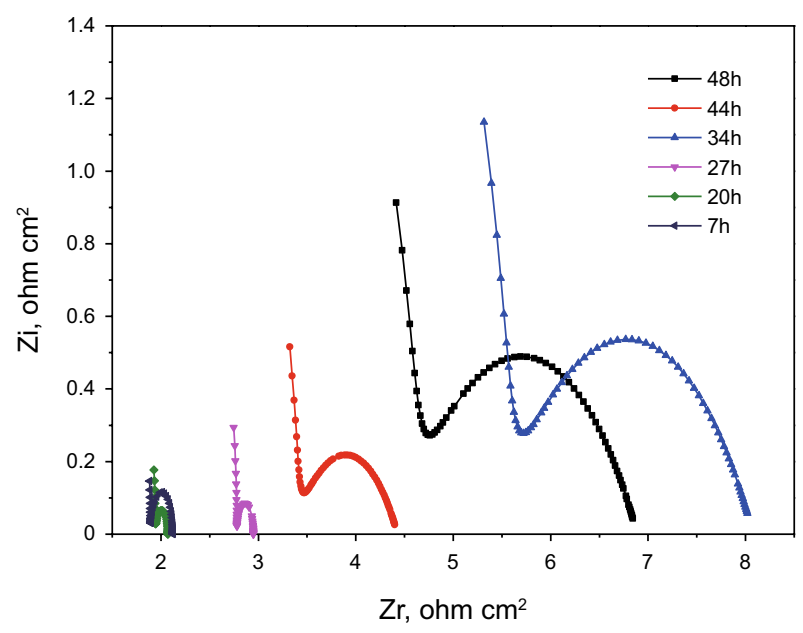

Fig. 12 Nyquist diagrams of experimental system under DC interference voltage of $-4 \mathrm{~V}$

in the gap, which results in the increase in the product and the increase in the impedance. After $34 \mathrm{~h}$, the fitting circuit appears $\mathrm{W}$, and the $\mathrm{W}$ value shows that the solution concentration gradient disappears in the coating. The barrier effect of the coating completely fails, the surface coating strips seriously, and the coating enters the period of exfoliation transition. Compared with the experimental system under $-2 \mathrm{~V}$ DC interference, the appearance of $\mathrm{W}$ under $-4 \mathrm{~V}$ DC interference is earlier, which indicates that when the interference current increases, the coating exfoliates rapidly.
The impedance evolution diagram of the experimental system under $-8 \mathrm{~V}$ DC interference is shown in Fig. 13. It can be seen that the impedance range and impedance fluctuation degree have been reduced with the increase in the DC interference voltage. The fitting results are given in Table 8. At the initial stage of the experiment, the charge transfer resistance $R_{\mathrm{t}}$ is small, indicating that the charge transfer process at the interface between the coating and the metal is relatively easy. At this stage, the coating has been preliminarily stripped. After $27 \mathrm{~h}$, the value of $R_{\mathrm{c}}$ increases obviously and the $R_{\mathrm{t}}$ value increases several times, indicating that the disbonding state of the coating entered a new stage, and the crevice corrosion intensifies, which results in the increase in corrosion products and the widening of the disbonding range. In comparison with the value of $R_{\mathrm{t}}$ in Table 7, the $R_{\mathrm{t}}$ decreases under $-8 \mathrm{~V}$ DC interference. It shows that the speed of the cathode disbonding in the $-8 \mathrm{~V}$ DC interference test is faster than that of $-4 \mathrm{~V}$, and the disbonding degree is greater.

The impedance evolution of the system under the DC interference of $-16 \mathrm{~V}$ is shown in Fig. 14. It can be seen that as the interference voltage continues to increase, the impedance range decreases. Therefore, from the total impedance range, it can be inferred that the degree of disbonding of the coating is greater than before. The fitting results are given in Table 9. In this experiment, $\mathrm{W}$ appears at $27 \mathrm{~h}$, and it indicates that the cathodic exfoliation speed of the coating is faster than that under the influence of $-16 \mathrm{~V} \mathrm{DC}$ interference.

Table 7 Circuit element fitting value under DC interference voltage of $-4 \mathrm{~V}$

\begin{tabular}{llllll}
\hline $\begin{array}{l}\text { Experimental } \\
\text { time, h }\end{array}$ & $\begin{array}{l}\text { Coating capacitor } \\
C_{\mathrm{c}}, \mathrm{F} \mathrm{cm}\end{array}$ & $\begin{array}{l}\text { Coating resistance } \\
R_{\mathrm{c}}, \Omega \mathrm{cm}^{2}\end{array}$ & $\begin{array}{l}\text { Electric double-layer } \\
\text { capacitor } R_{\mathrm{t}}, \Omega \mathrm{cm}^{2}\end{array}$ & $\begin{array}{l}\text { Electric double-layer } \\
\text { capacitor } C_{\mathrm{d}}, \mathrm{F} \mathrm{cm} \mathrm{cm}^{-2}\end{array}$ & $\begin{array}{l}\text { Diffusion impedance } \\
\text { of Warburg } W, \Omega \mathrm{cm}^{2}\end{array}$ \\
\hline 7 & $7.833 \mathrm{E}-8$ & 1.895 & 0.2287 & 0.001177 & - \\
20 & $9.071 \mathrm{E}-8$ & 1.944 & 0.128 & 0.1684 & - \\
27 & $7.428 \mathrm{E}-8$ & 2.78 & 0.1695 & 0.004562 & - \\
34 & $7.043 \mathrm{E}-8$ & 0.5497 & 2.582 & - & 0.016 \\
44 & $8.423 \mathrm{E}-8$ & 3.378 & 1.05 & - & 0.0438 \\
48 & $8.078 \mathrm{E}-8$ & 4.536 & 2.352 & - & 1.442 \\
\hline
\end{tabular}




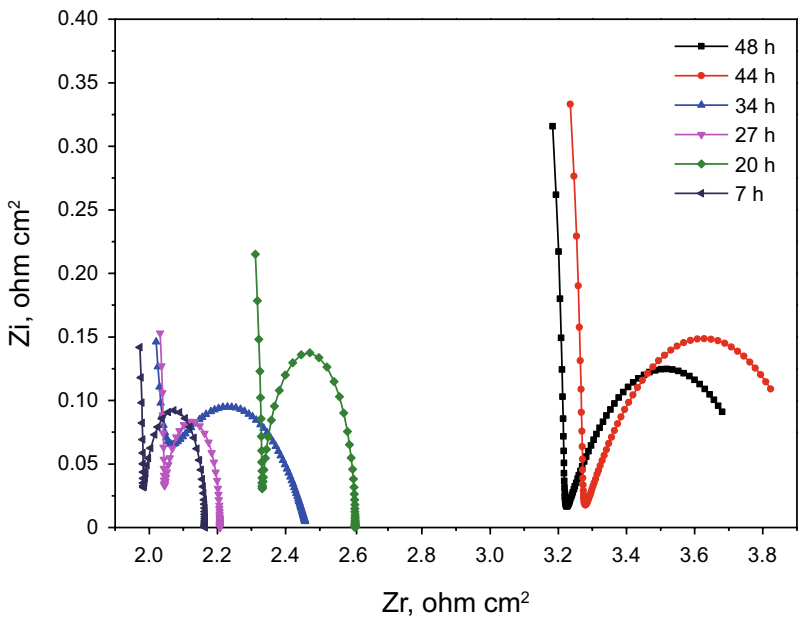

Fig. 13 Nyquist diagrams of experimental system under DC interference of $-8 \mathrm{~V}$

After finishing the experiments of the negative DC interference, the physical photographs of the samples are taken as shown in Fig. 15, and the disbonding distance of the anticorrosive layer is given in Table 10.

As shown in Fig. 15 and Table 10, when the epoxy powder coating was under the interference of negative DC stray current, the disbonding distance increases with the increase in voltage magnitude, and the results are consistent with the results obtained by the impedance spectroscopy.

\subsection{Corrosion morphology analysis}

At the end of the test period, after the electrode faces of the test group are cleaned up, corrosion morphology pictures are taken by the scanning electron microscope, as shown in Figs. 16, 17 and 18.

As shown in Fig. 16, few of small pits are observed on the surface of the electrodes without DC stray interference, and no obvious corrosion pits are observed. When DC interference voltage of $8 \mathrm{~V}$ is applied on the samples, a large number of corrosion pits appear on the surface of the metal, and a corrosion ditch has been formed. As shown in Fig. 18, the corrosion zone and the noncorrosion zone have a clear boundary line, and the boundary line is the edge region where the coating is peeled off. A large number of corrosion pits appear in the disbonding area, which is the characteristic of crevice corrosion and DC stray current corrosion. The microscopic appearance confirms the existence of anodic corrosion as the main reaction process in cathode disbonding. It also shows that under the disturbance of stray current, the degree of anode corrosion increases significantly, and the disbonding speed of the coating accelerates. That is, DC stray current promotes the cathodic disbonding of coatings.

\section{Conclusions}

1. In the experimental range, the positive DC stray interference is applied to the epoxy coating-metal system. The degree of anode corrosion increases under the interference of DC stray current. As increasing the voltage from 2 to $8 \mathrm{~V}$, the disbonding degree of the coating becomes larger and larger, and the disbonding time is advanced. When the DC interference voltage is $16 \mathrm{~V}$, the disbond-

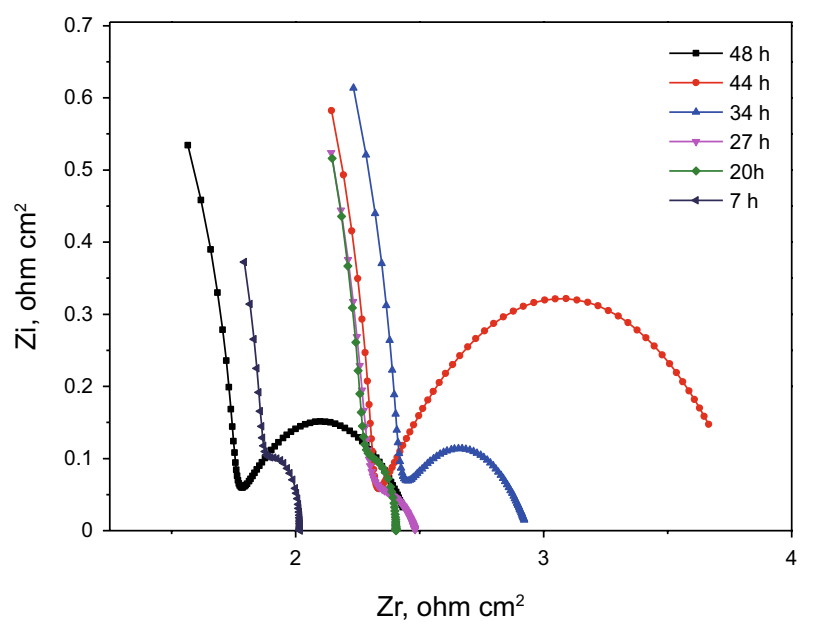

Fig. 14 Nyquist diagrams of experimental system under DC interference voltage of $-16 \mathrm{~V}$

Table 8 Circuit element fitting value in DC interference of $-8 \mathrm{~V}$

\begin{tabular}{llllll}
\hline $\begin{array}{l}\text { Experimental } \\
\text { time, h }\end{array}$ & $\begin{array}{l}\text { Coating capacitor } \\
C_{\mathrm{c}}, \mathrm{F} \mathrm{cm}\end{array}$ & $\begin{array}{l}\text { Coating resistance } \\
R_{\mathrm{c}}, \Omega \mathrm{cm}^{2}\end{array}$ & $\begin{array}{l}\text { Electric double-layer } \\
\text { capacitor } R_{\mathrm{t}}, \Omega \mathrm{cm}^{2}\end{array}$ & $\begin{array}{l}\text { Electric double-layer } \\
\text { capacitor } C_{\mathrm{d}}, \mathrm{F} \mathrm{cm} \mathrm{cm}^{-2}\end{array}$ & $\begin{array}{l}\text { Diffusion impedance } \\
\text { of Warburg } W, \Omega \mathrm{cm}^{2}\end{array}$ \\
\hline 7 & $6.907 \mathrm{E}-8$ & 1.983 & 0.1811 & 0.001086 & - \\
20 & $7.665 \mathrm{E}-8$ & 2.331 & 0.2731 & 0.001789 & - \\
27 & $7.023 \mathrm{E}-8$ & 2.044 & 0.1638 & 0.001064 & - \\
34 & $5.893 \mathrm{E}-8$ & 2.008 & 0.4543 & - & 0.04266 \\
44 & $6.046 \mathrm{E}-8$ & 3.268 & 0.7178 & - & 0.6066 \\
48 & $5.921 \mathrm{E}-8$ & 3.214 & 0.6023 & - & 0.6496 \\
\hline
\end{tabular}


Table 9 Circuit element fitting value under DC interference voltage of $-16 \mathrm{~V}$

\begin{tabular}{llllll}
\hline $\begin{array}{l}\text { Experimental } \\
\text { time, h }\end{array}$ & $\begin{array}{l}\text { Coating capacitor } \\
C_{\mathrm{c}}, \mathrm{F} \mathrm{cm}{ }^{-2}\end{array}$ & $\begin{array}{l}\text { Coating resistance } \\
R_{\mathrm{c}}, \Omega \mathrm{cm}^{2}\end{array}$ & $\begin{array}{l}\text { Electric double-layer } \\
\text { capacitor } R_{\mathrm{t}}, \Omega \mathrm{cm}^{2}\end{array}$ & $\begin{array}{l}\text { Electric double-layer } \\
\text { capacitor } C_{\mathrm{dl}}, \mathrm{F} \mathrm{cm} \mathrm{cm}^{-2}\end{array}$ & $\begin{array}{l}\text { Diffusion impedance } \\
\text { of Warburg } W, \Omega \mathrm{cm}^{2}\end{array}$ \\
\hline 7 & $2.098 \mathrm{E}-7$ & 1.869 & 0.1488 & 0.0002395 & - \\
20 & $2.018 \mathrm{E}-7$ & 2.271 & 0.1331 & 0.0002997 & - \\
27 & $2.021 \mathrm{E}-7$ & 2.255 & 0.2286 & - & 0.05787 \\
34 & $2.172 \mathrm{E}-7$ & 2.391 & 0.546 & - & 0.09327 \\
44 & $2.249 \mathrm{E}-7$ & 2.295 & 1.553 & - & 0.1385 \\
48 & $3.719 \mathrm{E}-7$ & 1.739 & 0.7294 & - & 0.1204 \\
\hline
\end{tabular}

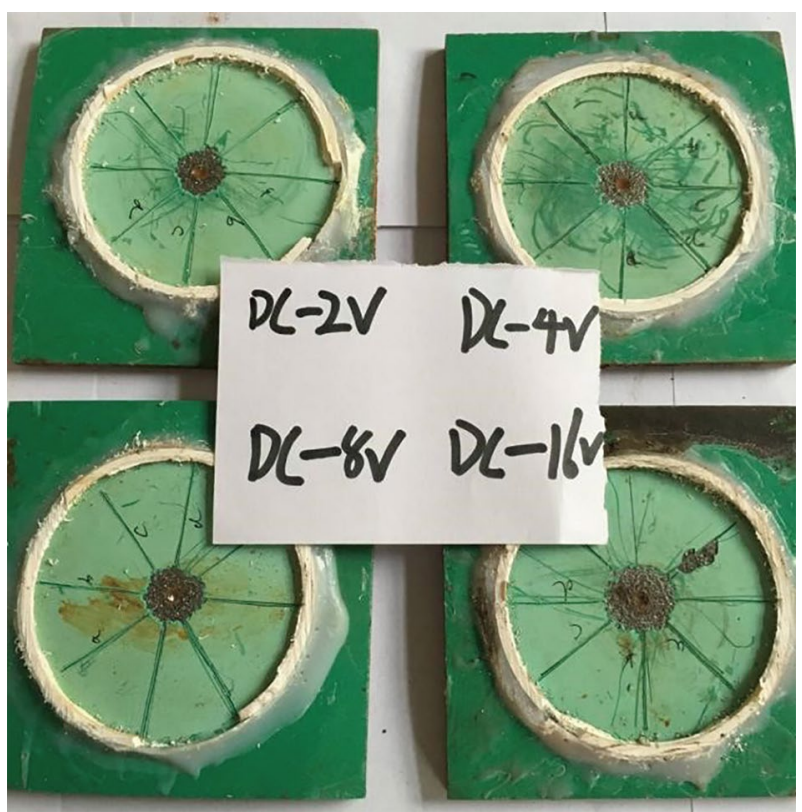

Fig. 15 Cathodic disbonding diagram with negative DC interference

Table 10 Disbonding distance of epoxy powder coating with negative DC interference

\begin{tabular}{llllll}
\hline DC interference, $\mathrm{V}$ & 0 & -2 & -4 & -8 & -16 \\
\hline Disbonding distance, $\mathrm{mm}$ & 4.5 & 5.6 & 6.1 & 6.7 & 8.2 \\
\hline
\end{tabular}

ing time of the coating delays and the degree of disbonding reduces. During this test, the anodic corrosion of the coating peeling tip played a leading role in coating peeling.

2. In the experimental range, the negative DC stray current is applied to the epoxy coating-metal substrate system, and it aggravates the cathodic disbonding of the epoxy powder coating The degree of cathodic disbonding increases with the increase in the interference magnitude, indicating that cathodic hydrogen evolution reaction played a leading role in the stripping process. In the presence of DC stray currents, attention should be

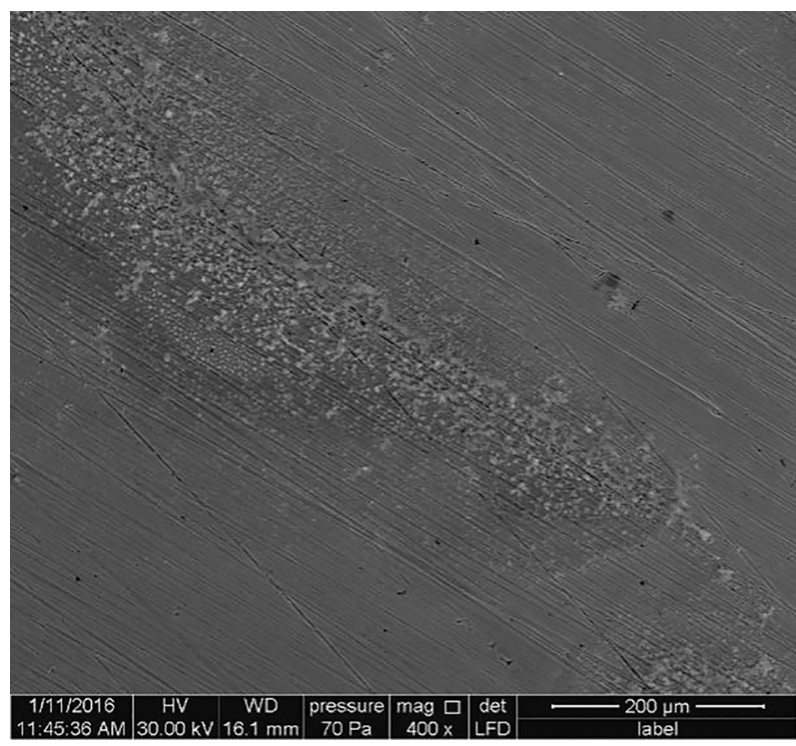

Fig. 16 Micromorphology of metal surface without interference test

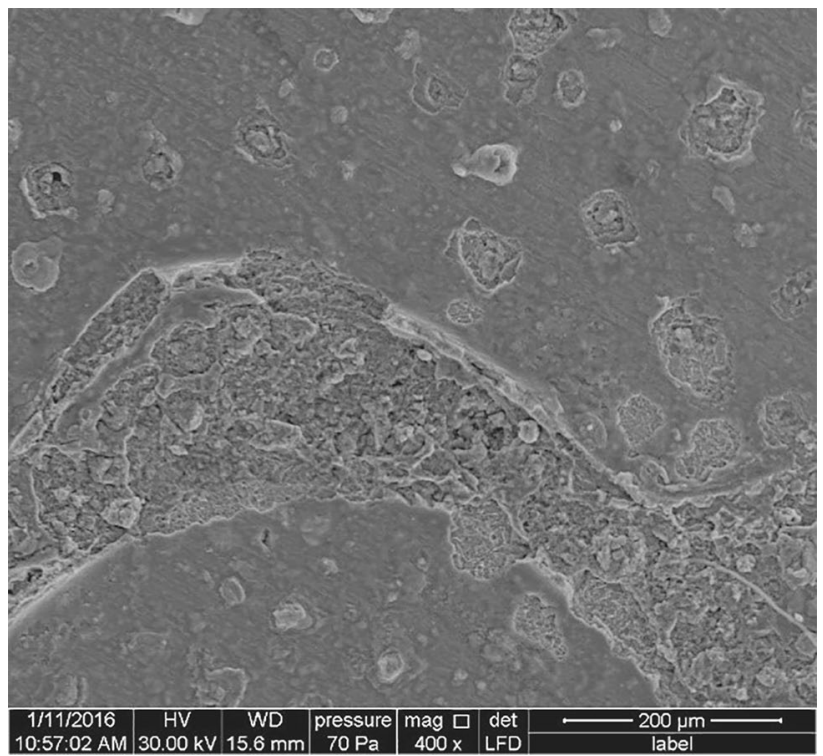

Fig. 17 Micromorphology of metal surface with DC interference voltage of $8 \mathrm{~V}$ 


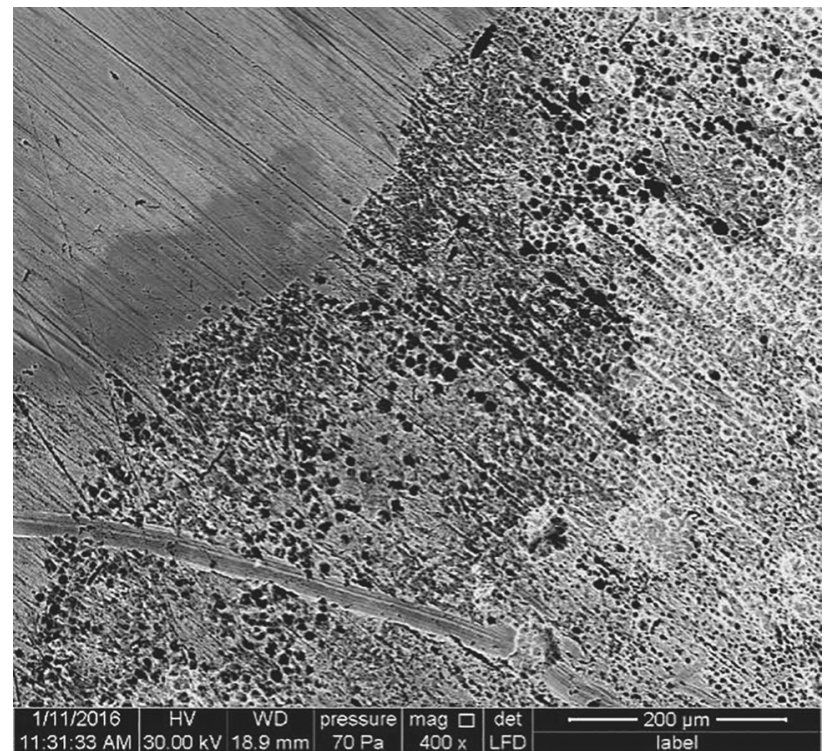

Fig. 18 Micromorphology of metal surface with DC interference voltage of $-8 \mathrm{~V}$

paid to the direction of the stray current applied to the pipe. The influence of the stray current direction on the disbonding performance of the coating is determined, and the adhesion of the coating or the drainage means or even the replacement of the coating type is adopted.

Acknowledgements The research work was supported by "Civil Aviation Safety Capacity Building Fund (Construction of safety evaluation system for multibranch complex annular apron pipe network)" and "the Fundamental Research Funds for the Central Universities (19CX05007A)."

\section{Compliance with ethical standards}

Conflict of interest The authors declare that there is no conflict of interests regarding the publication of this article.

Open Access This article is distributed under the terms of the Creative Commons Attribution 4.0 International License (http://creativeco mmons.org/licenses/by/4.0/), which permits unrestricted use, distribution, and reproduction in any medium, provided you give appropriate credit to the original author(s) and the source, provide a link to the Creative Commons license, and indicate if changes were made.

\section{References}

Bertolini L, Carsana M, Pedeferri P. Corrosion behaviour of steel in concrete in the presence of stray current. Corros Sci. 2007;49:1056-68. https://doi.org/10.1016/j.corsci.2006.05.048.

Bi HC, Sykes J. An investigation of cathodic oxygen reduction beneath an intact organic coating on mild steel and its relevance to cathodic disbonding. Prog Org Coat. 2015;87:83. https://doi. org/10.1016/j.porgcoat.2015.05.015.

Bin Muhd Noor NN, Yu K, Bharadwaj U, et al. Making use of external corrosion defect assessment (ECDA) data to predict DCVG. IR Drop Coat Defect Area. 2018;69:1237-56. https://doi. org/10.1002/maco.201810085.

Deflorian F, Rossi S. An EIS study of ion diffusion through organic coatings. Electrochim Acta. 2006;51:1736-44. https://doi. org/10.1016/j.electacta.2005.02.145.

Eltai EO, Scantlebury JD, Koroleva EV. Protective properties of intact unpigmented epoxy coated mild steel under cathodic protection. Prog Org Coat. 2012;73:8. https://doi.org/10.1016/j.porgc oat.2011.08.012.

Fürbeth W, Stratmann M. The delamination of polymeric coatings from electrogalvanised steel—a mechanistic approach: Part 1: delamination from a defect with intact zinc layer. Corros Sci. 2001;43:207-27. https://doi.org/10.1016/S0010-938X(00)00047 -0 .

Gamboa E, Coniglio N, Kurji R, et al. Hydrothermal ageing of X65 steel specimens coated with $100 \%$ solids epoxy. Prog Org Coat. 2013;76:1505-10. https://doi.org/10.1016/j.porgcoat.2013.06.002.

Kendig M, Addison R, Jeanjaquet S. The mechanism of cathodic disbonding of hydroxy-terminated polybutadiene on steel from acoustic microscopy and surface energy analysis. J Electrochem Soc. 1990;137:2690-7. https://doi.org/10.1149/1.2087011.

Kim YJ, Chai Y. Cathodic protection for steel beams strengthened with cfrp sheets. J Compos Constr. 2018;22:04018051. https:// doi.org/10.1061/(ASCE)CC.1943-5614.0000889.

Lee SH, Oh WK, Kim JG. Acceleration and quantitative evaluation of degradation for corrosion protective coatings on buried pipeline: Part II. Application to the evaluation of polyethylene and coaltar enamel coatings. Prog Org Coat. 2013;76:784-9. https://doi. org/10.1016/j.porgcoat.2012.12.006.

Li X, Bailey SI. A laboratory technique for evaluating marine splash zone corrosion. Adv Mater Res. 2012;347-353:3345. https://doi. org/10.4028/www.scientific.net/amr.347-353.3345.

Li Z, Li C, Qian H, et al. Corrosion behavior of X80 steel with coupled coating defects under alternating current interference in Alkaline environment. Materials. 2017. https://doi.org/10.3390/ma100 70720.

Luo JL, Lin CJ, Yang Q, et al. Cathodic disbonding of a thick polyurethane coating from steel in sodium chloride solution. Prog Org Coat. 1997;31:289-95. https://doi.org/10.1016/S0300 -9440(97)00086-6.

Mahdavian M, Ashhari S. Mercapto functional azole compounds as organic corrosion inhibitors in a polyester-melamine coating. Prog Org Coat. 2010;68:259-64. https://doi.org/10.1016/j.porgc oat.2010.04.002.

Miszczyk A, Schauer T. Electrochemical approach to evaluate the interlayer adhesion of organic coatings. Prog Org Coat. 2004. https:// doi.org/10.1016/j.porgcoat.2004.09.006.

Naderi R, Attar MM. Cathodic disbondment of epoxy coating with zinc aluminum polyphosphate as a modified zinc phosphate anticorrosion pigment. Prog Org Coat. 2010;69:392-5. https://doi. org/10.1016/j.porgcoat.2010.08.001.

Nikravesh B, Ramezanzadeh B, Sarabi AA, et al. Evaluation of the corrosion resistance of an epoxy-polyamide coating containing different ratios of micaceous iron oxide/Al pigments. Corros Sci. 2011;53:1592-603. https://doi.org/10.1016/j.corsci.2011.01.045.

Oliveira CG, Ferreira MGS. Ranking high-quality paint systems using EIS. Part II: defective coatings. Corros Sci. 2003;45:139-47. https ://doi.org/10.1016/S0010-938X(02)00089-6.

Parhizkar N, Shahrabi T, Ramezanzadeh B. Steel surface pre-treated by an advance and eco-friendly cerium oxide nanofilm modified by graphene oxide nanosheets; electrochemical and adhesion 
measurements. J Alloy Compd. 2018a;747:109-23. https://doi. org/10.1016/j.jallcom.2018.03.022.

Parhizkar N, Ramezanzadeh B, Shahrabi T. Corrosion protection and adhesion properties of the epoxy coating applied on the steel substrate pre-treated by a sol-gel based silane coating filled with amino and isocyanate silane functionalized graphene oxide nanosheets. Appl Surf Sci. 2018b;439:45-59. https://doi. org/10.1016/j.apsusc.2017.12.240.

Park JH, Lee GD, Ooshige H, Nishikata A, Tsuru T. Monitoring of water uptake in organic coatings under cyclic wet-dry condition. Corros Sci. 2003. https://doi.org/10.1016/S0010-938X(03)00024 $-6$.

Rahsepar M, Asgharzadeh M, Hadianfard MJ, et al. Failure analysis of disbondment of three-layer polyethylene coatings from the surface of buried steel pipelines. J Fail Anal Prev. 2015;15:604-11. https ://doi.org/10.1007/s11668-015-0014-9.

Rani N, Singh AK, Alam S, et al. Optimization of phosphate coating properties on steel sheet for superior paint performance. J Coat Technol Res. 2012;9:629-36. https://doi.org/10.1007/s1199 8-012-9395-9.

Shi W, Lyon SB. Investigation using localised SVET into protection at defects in epoxy coated mild steel under intermittent cathodic protection simulating inter-tidal and splash zones. Prog Org Coat. 2017;102:66-70. https://doi.org/10.1016/j.porgcoat.2017.04.035.

Sørensen PA, Kii S, Dam-Johansen K, et al. Influence of substrate topography on cathodic delamination of anticorrosive coatings.
Prog Org Coat. 2008;64:142-9. https://doi.org/10.1016/j.porgc oat.2008.08.027.

Sørensen PA, Dam-Johansen K, Weinell CE, et al. Cathodic delamination of seawater-immersed anticorrosive coatings: mapping of parameters affecting the rate. Prog Org Coat. 2010;68:283-92. https://doi.org/10.1016/j.porgcoat.2010.03.012.

Teng S, Gao Y, Cao F, et al. Zinc-reduced graphene oxide for enhanced corrosion protection of zinc-rich epoxy coatings. Prog Org Coat. 2018;123:185-9. https://doi.org/10.1016/j.porgcoat.2018.07.012.

Wang K, Varela FB, Tan MY. An array of multielectrodes for locating, visualizing, and quantifying stray current corrosion. Corrosion. 2018;74:1093-101. https://doi.org/10.5006/2828.

Xi ZD. Discussion on natural gas pipeline anticorrosion technology. Chem Equip Technol. 2008;29:49-50. https://doi.org/10.16759 /j.cnki.issn.1007-7251.2008.06.012.

Yan MC, Wang JQ, Han EH, et al. Characteristics and evolution of thin layer electrolyte on pipeline steel under cathodic protection shielding disbonded coating. Acta Metall Sin. 2014;50:1137-45. https://doi.org/10.11900/0412.1961.2014.00156.

Yao JD, Liang HC, Huang NB, et al. Research progress in influencing factors of cathodic disbandment of organic coatings. Surf Technol. 2014;43:137-43. https://doi.org/10.16490/j.cnki. issn.1001-3660.2014.03.026. 